\title{
OPEN Invasion, establishment, and spread of invasive mosquitoes from the Culex coronator complex in urban areas of Miami-Dade County, Florida
}

André B. B. Wilke ${ }^{1 凶}$, Chalmers Vasquez ${ }^{2}$, Gabriel Cardenas ${ }^{1}$, Augusto Carvajal ${ }^{2}$, Johana Medina ${ }^{2}$, William D. Petrie ${ }^{2} \&$ John C. Beier ${ }^{1}$

Species from the Culex coronator complex are Neotropical species and potential vectors of Saint Louis and West Nile viruses. Culex coronator was first described in Trinidad and Tobago in the early twentieth century and since then it has invaded and has been reported established in most countries of the Americas. Species from the Culex coronator complex were first detected in the United States in the state of Louisiana in 2004 and were subsequently detected in Florida in 2005, reaching MiamiDade County in 2008. We hypothesize that species from the $C x$. coronator complex are adapting to urban environments in Miami-Dade County, Florida, and are becoming more present and abundant in these areas. Therefore, our objective was to investigate the patterns of the presence and abundance of species from the $C x$. coronator complex in the urban areas of Miami-Dade County. Here we used weekly data comprised of 32 CDC traps from 2012 to 2020 and 150 BG-Sentinel traps from 2016 to 2020. A total of 34,146 female mosquitoes from the $C x$. coronator complex were collected, 26,138 by CDC traps and 8008 by BG-Sentinel traps. While the number of CDC traps that were positive was relatively constant at 26-30 positive traps per year, the number of positive BG-Sentinel traps varied substantially from 50 to 87 positive traps per year. Furthermore, the heat map and logistic general linear model for repeated measures analyses showed a significant increase in both the distribution and abundance of mosquitoes from the $C x$. coronator complex, indicating that these species are becoming more common in anthropized habitats being able to thrive in highly urbanized areas. The increase in the distribution and abundance of species from the $C x$. coronator complex is a major public health concern. The ability of species from the $C x$. coronator complex to benefit from urbanization highlights the need to better understand the mechanisms of how invasive vector mosquito species are adapting and exploiting urban habitats.

Vector-borne diseases pose a major threat to public health ${ }^{1-3}$. Currently, arbovirus outbreaks are becoming more frequent worldwide. Dengue is endemic in 128 countries infecting millions of people every year ${ }^{4,5}$. Even though it has stabilized in recent years, the incidence of West Nile virus (WNV) is on the rise due to a significant increase in the number of human infections, especially in North America ${ }^{6-8}$. Saint Louis encephalitis (SLEV) is also an epidemiologically relevant arbovirus. It can be found in most countries in the Americas ranging from Canada to Argentina. Most SLEV human cases occur in the United States, and from the 72 SLEV infections reported from 2010 to 2019,6 resulted in death ${ }^{9}$.

The increase in the incidence of vector-borne diseases can be partially attributed to the increase in presence, abundance, and distribution of vector mosquito species in urban areas ${ }^{10,11}$. These species often have a great potential to invade and colonize new areas and greatly benefit from biotic homogenization processes and biodiversity loss caused by urbanization ${ }^{12-14}$. As a consequence, the increased contact between vector mosquitoes and human hosts heightens the exposure of humans to dangerous arboviruses ${ }^{15}$. Invasive mosquito species are

${ }^{1}$ Department of Public Health Sciences, Miller School of Medicine, University of Miami, 1120 Northwest 14th Street, Miami, FL 33136, USA. ${ }^{2}$ Miami-Dade County Mosquito Control Division, Miami, FL, USA. ${ }^{\square}$ email: axb1737@med.miami.edu 


\begin{tabular}{|l|l|l|l|l|}
\hline \multirow{2}{*}{ Date } & \multicolumn{2}{l|}{ CDC traps } & \multicolumn{2}{l|}{ BG-sentinel traps } \\
\cline { 2 - 5 } & Mosquitoes collected & Positive traps & Mosquitoes collected & Positive traps \\
\hline $07 / 2012-06 / 2013$ & 2176 & 29 & N/A & N/A \\
\hline $07 / 2013-06 / 2014$ & 3178 & 28 & N/A & N/A \\
\hline $07 / 2014-06 / 2015$ & 3514 & 27 & N/A & N/A \\
\hline $07 / 2015-06 / 2016$ & 3813 & 26 & N/A & N/A \\
\hline $07 / 2016-06 / 2017$ & 1017 & 29 & 1687 & 50 \\
\hline $07 / 2017-06 / 2018$ & 4439 & 29 & 3250 & 72 \\
\hline $07 / 2018-06 / 2019$ & 3270 & 30 & 2071 & 87 \\
\hline $07 / 2019-06 / 2020$ & 4731 & 30 & 1000 & 65 \\
\hline
\end{tabular}

Table 1. Species from the Culex coronator complex collected in Miami-Dade County, Florida from 2012 to 2020 by the CDC and BG-Sentinel traps.

among the most important vectors ${ }^{16-20}$. Species such as Aedes aegypti (L.), Aedes albopictus (Skuse), and Culex quinquefasciatus Say can rapidly adapt to and benefit from anthropogenic alterations in the environment, being able to invade and colonize urban areas ${ }^{21-24}$.

Culex coronator Dyar and Knab is a highly invasive Neotropical species ${ }^{16}$ that was first observed in Trinidad and Tobago in $1906^{25}$. It belongs to the Culex coronator complex with another four sibling species Culex camposi Dyar, Culex ousqua Dyar, Culex usquatissimus Dyar, and Culex usquatus Dyar ${ }^{26}$. These species can occur in sympatry and are only distinguishable by a few morphological features present at the larval stage and in the male genitalia ${ }^{26,27}$.

Species from the Culex coronator complex have an unknown epidemiological role in the transmission of arboviruses to humans. However, they have been found to be competent vectors of $\mathrm{WNV}^{28,29}$ and are considered potential vectors of SLEV ${ }^{30,31}$. They have greatly expanded their range and are now present in most countries of the Americas. Since its first detection in Louisiana in 2004, species from the Cx. coronator complex are now considered established in most of the southern states in the United States ${ }^{16}$. Even though the invasion of species from the Cx. coronator complex is well documented in the United States, the mechanisms (e.g., changes in their ecology and behavior, adaptation to local artificial aquatic habitats and resources, etc.) employed on their invasion, establishment, and colonization of new areas remain largely unknown.

Several factors could have contributed to the dispersion of species from the $C x$. coronator complex over large geographic areas. However, their ability to thrive and establish themselves in urban areas that have undergone abrupt and substantial anthropogenic land use and land cover transformations indicates that these species are able to exploit the resources present in urban areas at the microgeographic scale (i.e., neighborhood level). Furthermore, many mosquito vector species have the potential to be passively or actively introduced into urban $\operatorname{areas}^{32-34}$, but only a selected few species are able to reach high abundances. It is clear that being able to exploit the resources available in urban areas at the microgeographic scale is crucial for their establishment and proliferation in urban areas ${ }^{14}$. Determining to what extent species from the $C x$. coronator complex are expanding their range in urban areas at the microgeographic scale and whether they are increasing their contact with human hosts in the process is essential for the development of effective and targeted mosquito control strategies.

Species from the Culex coronator complex have only recently been detected in Florida with the first reports dating from 2005, reaching Miami-Dade County in $2008^{35}$. Since then they have been found breeding in artificial aquatic habitats such as pools, garbage cans, and fountains ${ }^{36}$ and have become abundant in the urban areas of the county ${ }^{13}$. We hypothesize that species from the $C x$. coronator complex are adapting to urban environments in Miami-Dade County, Florida, and are becoming gradually more present and abundant in those areas. Therefore, our objective was to investigate the patterns of the presence and abundance of species from the $C x$. coronator complex in the urban areas of Miami-Dade County.

\section{Results}

A total of 34,146 female specimens from the Cx. coronator complex were collected by the Miami-Dade Mosquito Control surveillance system, 26,138 by CDC traps from July 2012 to June 2020, and 8,008 by BG-Sentinel traps from July 2016 to June 2020 . From the 32 CDC traps in the surveillance system, species from the Cx. coronator complex were collected by a minimum of 26 traps and a maximum of 30 traps in a given year. On the other hand, from the $150 \mathrm{BG}$-Sentinel traps in the surveillance system, species from the $C x$. coronator complex were collected by a minimum of 50 and a maximum of 87 traps in a given year (Table 1). Our results also indicate that despite having only recently been detect in Miami-Dade, species from the $C x$. coronator complex are increasing their range and abundance in urban areas of the county, and even though they are not as abundant and widespread as Ae. aegypti or CX. quinquefasciatus, they should be considered in future mosquito control interventions (Table 2).

The heat map based on the Kernel density estimator of the relative abundance of species from the Cx. coronator complex collected by the CDC traps indicates that since their first detection in 2008, they have become abundant in the peri-urban areas of Miami-Dade County. The presence and abundance of specimens from the Cx. coronator complex remained constant from 2012 to 2020 indicating that these species are adapted to the conditions and resource availability found in those areas. Furthermore, specific locations with optimum conditions continually yielded high abundances of species from the $C x$. coronator complex throughout all 8 years of data obtained by the CDC traps (Fig. 1). 


\begin{tabular}{|c|c|c|c|c|c|c|c|c|c|c|}
\hline \multirow[b]{2}{*}{ Date } & \multicolumn{2}{|c|}{ Aedes aegypti } & \multicolumn{2}{|c|}{ Aedes albopictus } & \multicolumn{2}{|c|}{ Culex coronator } & \multicolumn{2}{|c|}{ Culex nigripalpus } & \multicolumn{2}{|c|}{ Culex quinquefasciatus } \\
\hline & $\begin{array}{l}\text { Mosquitoes } \\
\text { collected }\end{array}$ & Positive traps & $\begin{array}{l}\text { Mosquitoes } \\
\text { collected }\end{array}$ & Positive traps & $\begin{array}{l}\text { Mosquitoes } \\
\text { collected }\end{array}$ & Positive traps & $\begin{array}{l}\text { Mosquitoes } \\
\text { collected }\end{array}$ & Positive traps & $\begin{array}{l}\text { Mosquitoes } \\
\text { collected }\end{array}$ & Positive traps \\
\hline $\begin{array}{l}07 / 2016- \\
06 / 2017\end{array}$ & 45,720 & 133 & 177 & 32 & 1687 & 50 & 2835 & 79 & 121,606 & 133 \\
\hline $\begin{array}{l}07 / 2017- \\
06 / 2018\end{array}$ & 37,004 & 131 & 289 & 53 & 3250 & 72 & 18,171 & 118 & 169,495 & 131 \\
\hline $\begin{array}{l}\text { 07/2018- } \\
06 / 2019\end{array}$ & 37,515 & 148 & 542 & 60 & 2071 & 87 & 3772 & 98 & 107,480 & 148 \\
\hline $\begin{array}{l}07 / 2019- \\
06 / 2020\end{array}$ & 32,224 & 148 & 626 & 57 & 1000 & 65 & 9737 & 127 & 92,973 & 148 \\
\hline
\end{tabular}

Table 2. Epidemiologically relevant mosquito vector species collected in the urban areas of Miami-Dade County, Florida from 2016 to 2020 by the BG-Sentinel traps.
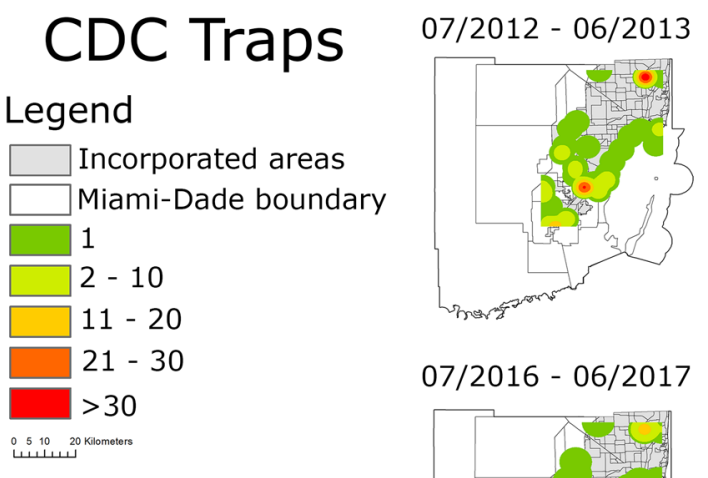

$07 / 2016-06 / 2017$

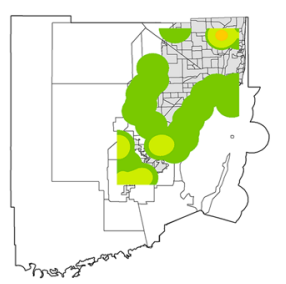

$07 / 2013-06 / 2014$

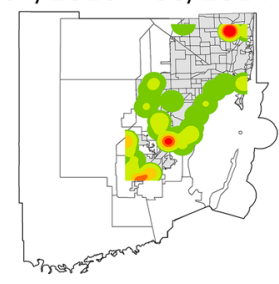

$07 / 2017-06 / 2018$

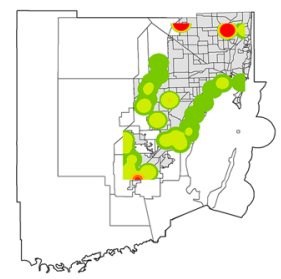

$07 / 2014-06 / 2015$

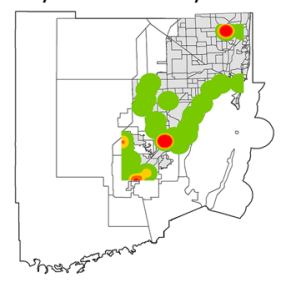

$07 / 2018-06 / 2019$

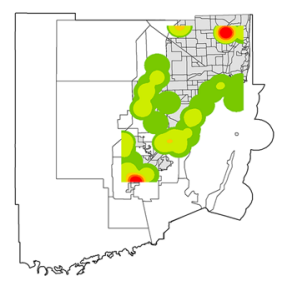

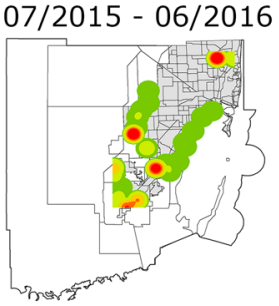

$07 / 2019-06 / 2020$

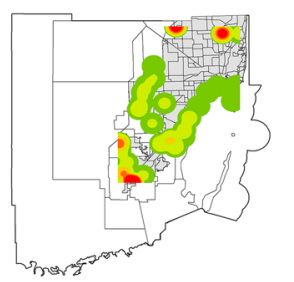

Figure 1. Heat map based on the relative abundance of species from the Culex coronator complex collected by the 32 CDC traps in Miami-Dade County, Florida from July 2012 to June 2020. The color gradient represents the sum of species from the Cx. coronator complex collected by each CDC trap in a 12 months period. The figure was produced using ArcGIS 10.2 (Esri, Redlands, CA), using freely available layers from the Miami-Dade County's Open Data Hub-https://gis-mdc.opendata.arcgis.com/.

The heat map based on the Kernel density estimator of the relative abundance of species from the Cx. coronator complex collected by the BG-Sentinel traps showed a clear increase in their presence and abundance in urban areas. Since 2016, when the surveillance system results showed that species from the $C x$. coronator complex had limited presence and abundance relegated to specific and well-defined locations in the county, they have greatly increased their presence and abundance over the years. Our results showed a gradual increase in presence and abundance of species from the $C x$. coronator complex in urban areas. The increase of the kernels of the heat maps indicates that more traps collected more species from the $C x$. coronator complex in a more consistent way over the years culminating in the colonization of most of Miami-Dade urban areas by Cx. coronator in 2020. Furthermore, our results indicate that even though fewer mosquitoes from the $C x$. coronator complex were collected from July 2019 to June 2020 than from July 2016 to June 2017 they were more homogeneously distributed throughout Miami-Dade. As a result, the kernel density heatmap shows larger and more widespread dots ranging from 1 to 20 mosquitoes per trap (Fig. 2).

The logistic general linear repeated measures model of the mean of positive BG-Sentinel traps for species from the Culex coronator complex collected from July 2016 to June 2020 resulted in a significant quadratic effect over the 4 years of collections yielding a $P$ value of $<0.001$. The estimated $95 \%$ confidence interval standard errors did not show a linear increase but a quadratic curve, in which more BG-Sentinel traps collected significantly more mosquitoes from the Cx. coronator complex from July 2017 to June 2018 and July 2018 to June 2019 when compared to the number of positive traps from July 2016 to June 2017. On the other hand, even though more traps were positive for species from the Cx. coronator complex from July 2019 to June 2020 when compared to July 2016 to June 2017 the difference was not significant (Fig. 3). 
BG-Sentinel Traps

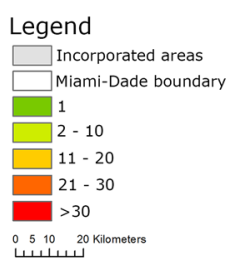

0.510 20 Kliometers

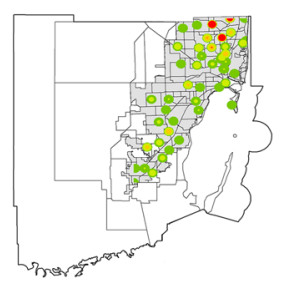

07/2016 - 06/2017

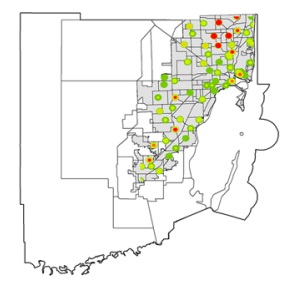

07/2017 - 06/2018

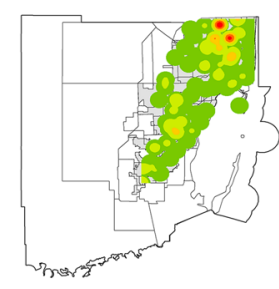

07/2018 - 06/2019

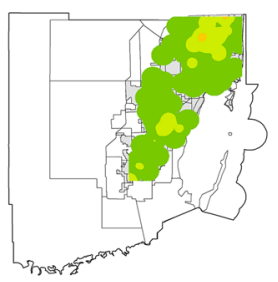

$07 / 2019$ - 06/2020

Figure 2. Heat map based on the relative abundance of species from the Culex coronator complex collected by the BG-Sentinel traps in Miami-Dade County, Florida from July 2016 to June 2020. The color gradient represents the sum of species from the Cx. coronator complex collected by each BG-Sentinel trap in a 12 months period. The figure was produced using ArcGIS 10.2 (Esri, Redlands, CA), using freely available layers from the Miami-Dade County's Open Data Hub-https://gis-mdc.opendata.arcgis.com/.

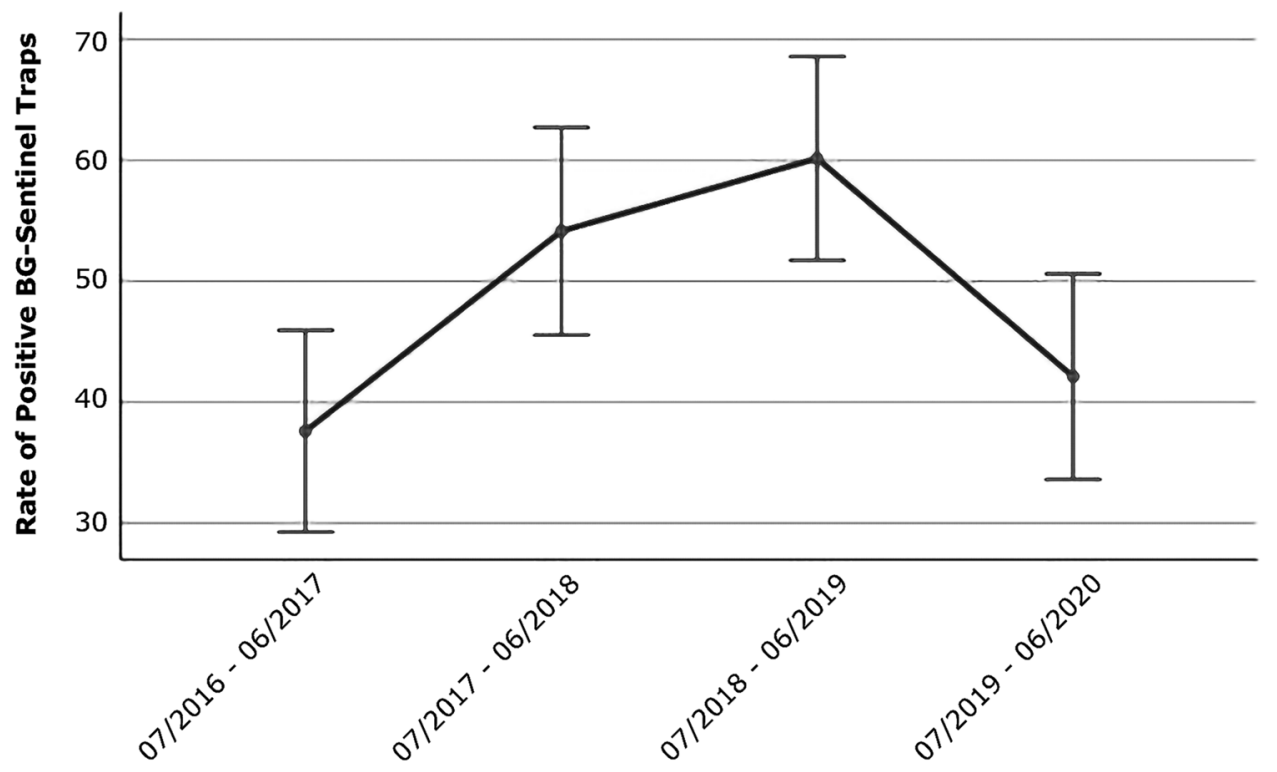

Figure 3. Graph of means of positive BG-Sentinel traps for species from the Culex coronator complex collected from July 2016 to June 2020 in Miami-Dade County, Florida. Each point displays the mean value; the whisker interval represents a 95\% confidence interval standard error; the Quadratic effect was significant with a $P$ value of $<0.001$.

\section{Discussion}

Anthropogenic changes in the environment are major drivers of biotic homogenization of species, greatly benefiting species that can exploit the resources available in urban areas. Our results show that species from the $C x$. coronator complex successfully invaded and colonized Miami-Dade County becoming one of the most abundant mosquito species with epidemiological relevance. Since its introduction in Miami-Dade County in 2008, species from the $C x$. coronator complex gradually increased their presence and abundance. First, they increased their presence and abundance in the peri-urban areas, then they subsequently invaded and colonized the urban areas of Miami-Dade, ranging from residential areas with low population densities to highly urbanized areas comprised mostly of skyscrapers. Regardless of the availability of several species occurrence record studies, to our knowledge, this is the first study to assess the microgeographic demographic expansion of species from the $C x$. coronator complex in urban areas in the United States.

The increase in presence and abundance of species from the Cx. coronator complex in Miami-Dade represents a major public health concern. One of the side effects of urbanization is the health disparities due to monetary inequities resulting in underserved populations that are more exposed to infectious diseases, including vectorborne. People living in lower-income neighborhoods are more exposed to vector mosquitoes ${ }^{37}$. Some houses in these under-served neighborhoods do not have air conditioning or screens on windows, and for these reasons, people tend to spend more time outdoors and are more exposed to mosquito bites during the night when species from the $C x$. coronator complex are more active ${ }^{38}$. Furthermore, these areas have higher concentrations of homeless people that are constantly exposed to vector mosquito bites. The size of the homeless population fluctuates in Miami-Dade during the year, increasing substantially during the colder months of the year due to homeless people seeking warmer environments ${ }^{39}$. The homeless migration to Miami-Dade coincides with bird 
migration passing through Miami migrating south. The introduction of another mosquito vector species such as the species from the $C x$. coronator complex that are adapted to urban environments and are recognized as an efficient vector of WNV can drastically increase the likelihood of WNV spillover from birds to humans ${ }^{13,28}$.

The mechanisms used by invasive species to adapt their ecology and behavior to urban environments are not fully understood. It is still unknown what allows a given species to successfully invade and colonize a new area. For example, the invasive species Culex panocossa Dyar has been detected in great numbers in natural areas in Miami-Dade County ${ }^{40}$ but has not been detected in peri-urban and urban areas ${ }^{13}$. The most widely accepted hypothesis is that $C x$. panocossa close association with water lettuce plants, commonly found in natural areas in Miami-Dade but not in peri-urban and urban areas, is a limiting factor for its expansion into urban areas ${ }^{41}$. Furthermore, regional variation has also to be taken into consideration. For example, even though species from the $C x$. coronator complex are considered to be invasive vector species well adapted to urban environments in the United States ${ }^{16}$, in Brazil they are not commonly found in urban areas ${ }^{42-44}$.

Even though invasion, establishment, and colonization of new areas by vector mosquito species have been well documented ${ }^{16,35}$, there are currently no contingency plans or specific guidelines to deter and mitigate both mosquito geographic and demographic expansions. Our results showed that since they were abundantly found in the outskirts of the urbanized areas of Miami-Dade and commonly collected by the CDC traps, species from the $C x$. coronator complex were able to gradually colonize most of Miami-Dade incorporated areas in less than a decade, as uncovered by the results obtained by the BG-Sentinel traps, highlighting the need for the development of integrated and effective mosquito surveillance and control strategies at the national level rather than a more localized approach at the county level. Those measures together with the Integrated Vector Management (IVM) in the form of source reduction of potential artificial and natural aquatic habitats, improvement of environmental ordinance guidelines and policies, and adequate sanitary infrastructure, especially for underserved populations to attenuate social inequities are crucial for thwarting the invasion and expansion of vector mosquito species and prevent non-endemic areas from becoming endemic for arboviruses ${ }^{45,46}$.

The results of this study can be used to increase awareness of the danger of the introduction of invasive species. The implementation of mosquito surveillance systems capable of detecting invasive species at an early stage is paramount for the development of effective contingency plans and targeted mosquito control strategies. In this context, Miami-Dade is a gateway city and consequently has the potential to export invasive mosquito species to other parts of the contiguous United States that have suitable resources and conducive conditions to support mosquito populations.

Recently, the invasive species Aedes vittatus (Bigot, 1861), a primary vector of arbovirus in Europe and Asia, has been detected in Cuba and the Dominican Republic. Subsequent phylogenetic analysis indicated that Ae. vittatus had been introduced multiple times into the Caribbean region ${ }^{47}$. Due to the increased connectivity between the Caribbean region and Miami-Dade, the introduction of Ae. vittatus to Miami-Dade is considered unavoidable and should be monitored closely.

The continuous environmental degradation due to anthropogenic changes in the environment is a major driver for the introduction, colonization, and spread of vector mosquito species. A new and improved mosquito control framework is urgently needed to prevent both the introduction of mosquito vector species to nonendemic regions (i.e., the introduction of Ae. vittatus in the United States) and to manage the spread of invasive species that have already been introduced and are spreading to new areas (i.e., range expansion of species from the $C x$. coronator complex in the United States and Ae. albopictus in Europe $\left.{ }^{16}\right)$.

Essential information about species from the $C x$. coronator complex biology, behavior, and physiology is currently lacking. Most of the information currently available has been acquired through adult mosquito surveillance systems that focus on female mosquitoes. Due to caveats in the morphological identification, the correct identification of adult specimens from the $C x$. coronator complex is only possible by observing differences in the male genitalia. For this reason, it is so far unknown what species from the $C x$. coronator complex are present in the United States, and if one or more species from the $C x$. coronator complex are more prone to adapt to urban environments than others and should be targeted in control strategies. The correct species identification is critical for the precise assessment of behavioral traits such as blood- and sugar-feeding, mating, resting, etc. Without that information, it is impossible to determine what environmental resources are driving the population dynamics of $C x$. coronator and the other species in the Cx. coronator complex.

This study can serve as a stepping stone to future studies to determine what invasive mosquito vector species represent a risk to public health and should be targeted by mosquito control operations. Furthermore, there is no coordinated mosquito surveillance at the international and national level, which is essential to prevent the introduction and spread of invasive mosquito vector species to new areas. The introduction of invasive mosquito vector species can have an unpredictable impact on public health and represent one of the most important challenges in mosquito control and vector-borne disease transmission.

\section{Methods}

Study design. This study used a longitudinal design to assess the presence and relative abundance of species from the Cx. coronator complex in peri-urban and urban areas in Miami-Dade County, Florida. Miami-Dade is the most populous county in Florida, with approximately 3 million people. Current predictions indicate that Miami-Dade will gain 700,000 more residents by $2030^{48}$ causing a substantial increase in urbanization processes. Miami-Dade has a year-round wet sub-tropical climate that is conducive for the year-round proliferation of mosquitoes ${ }^{13}$. Miami-Dade is also a destination for many bird species that are migrating south seeking warmer weather conditions ${ }^{49}$. All those factors together make Miami-Dade a hotspot for WNV transmission. In 2020 alone, 59 locally transmitted human cases of WNV were reported in Miami-Dade by the Florida Department of Health ${ }^{50}$. 
A

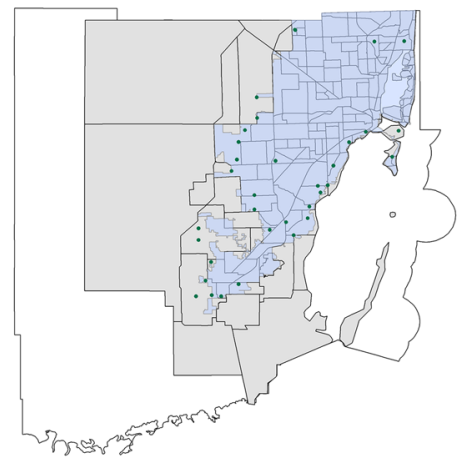

CDC traps

Legend

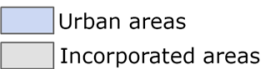

$\square$ Miami-Dade boundary

- CDC trap

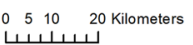

Figure 4. Map of Miami-Dade County, Florida. (A) Location of the 32 CDC traps; and (B) location of the 150 BG-Sentinel traps. The figure was produced using ArcGIS 10.2 (Esri, Redlands, CA), using freely available layers from the Miami-Dade County's Open Data Hub-https:/gis-mdc.opendata.arcgis.com/.

Mosquito collection. We used data obtained by BG-Sentinel (Biogents AG, Regensburg, Germany), and CDC traps. CDC traps were located in natural areas in the outskirts of the incorporated urban areas of MiamiDade County, whereas BG-Sentinel traps were located in urban areas ${ }^{13}$. A total of 133 BG-Sentinel traps were deployed from July 2016 to June 2018. In July 2018, 17 new BG-Sentinel traps were added totaling 150 BGSentinel traps that were used from July 2018 to June 2020. A total of 32 CDC traps were deployed from July 2012 to June 2020 (Fig. 4) ${ }^{13}$. All traps were deployed weekly for $24 \mathrm{~h}$ and baited with $\mathrm{CO}_{2}$ using a container filled with $1 \mathrm{~kg}$ of dry ice pellets ${ }^{13,51}$. All collected mosquitoes were transported to the Miami-Dade County Mosquito Control Laboratory and morphologically identified to species using taxonomic keys ${ }^{52}$. Since both the BG-Sentinel and the CDC trap mainly attract females seeking hosts male mosquitoes were not included in the analysis.

Geospatial analysis. We used a Kernel density estimator to calculate the magnitude-per-unit area (number of input per point (i.e., species from the $C x$. coronator complex relative abundance)) from both the BG-Sentinel and CDC traps using ArcGIS 10.2 (Esri, Redlands, CA) ) $^{53}$. We used the geodesic method for densities in square kilometers with an output cell size of 0.001 . We used freely available layers from the Miami-Dade County's Open Data Hub-https://gis-mdc.opendata.arcgis.com/. We used a logistic general linear model (GLM) for repeated measures for the number of BG-Sentinel traps that collected mosquitoes from the $C x$. coronator complex on each year (positive traps) as the dependent variable, with time as the independent variable. Since this study posed less than minimal risk to participants and did not involve endangered or protected species the Institutional Review Board at the University of Miami determined that the study be exempt from institutional review board assessment (IRB Protocol Number: 20161212).

Received: 19 March 2021; Accepted: 1 July 2021

Published online: 16 July 2021

\section{References}

1. Wilke, A. B. B., Beier, J. C. \& Benelli, G. Complexity of the relationship between global warming and urbanization-An obscure future for predicting increases in vector-borne infectious diseases. Curr. Opin. Insect Sci. 35, 1-9 (2019).

2. Franklinos, L. H. V., Jones, K. E., Redding, D. W. \& Abubakar, I. The effect of global change on mosquito-borne disease. Lancet Infect. Dis. 19, e302-e312 (2019).

3. WHO. Regional plan of action 2019-2023 for implementation of the global vector control response 2017-2030. World Health Organization. https://apps.who.int/iris/handle/10665/325805 (2019).

4. Brady, O. J. \& Hay, S. I. The global expansion of dengue: How Aedes aegypti mosquitoes enabled the first pandemic arbovirus. Annu. Rev. Entomol. 65, 191-208 (2020).

5. Bhatt, S. et al. The global distribution and burden of dengue. Nature 496, 504-507 (2013).

6. Rosenberg, R. et al. Vital signs: Trends in reported vectorborne disease cases-United States and Territories, 2004-2016. Morb. Mortal. Wkly. Rep. 67, 496-501 (2018).

7. Hadfield, J. et al. Twenty years of West Nile virus spread and evolution in the Americas visualized by Nextstrain. PLoS Pathog. 15, e1008042 (2019).

8. Ronca, S. E., Murray, K. O. \& Nolan, M. S. Cumulative incidence of West Nile virus infection, continental United States, $1999-2016$. Emerg. Infect. Dis. 25, 325-327 (2019).

9. CDC. Saint Louis Encephalitis. https://www.cdc.gov/sle/index.html.

10. Kraemer, M. U. G. et al. The global compendium of Aedes aegypti and Ae. albopictus occurrence. Sci. Data 2, 150035 (2015).

11. Messina, J. P. et al. A global compendium of human dengue virus occurrence. Sci. Data 1, 140004 (2014).

12. Knop, E. Biotic homogenization of three insect groups due to urbanization. Glob. Change Biol. 22, $228-236$ (2016).

13. Wilke, A. B. B. et al. Community composition and year-round abundance of vector species of mosquitoes make Miami-Dade County, Florida a receptive gateway for arbovirus entry to the United States. Sci. Rep. 9, 8732 (2019).

14. Wilke, A. B. B. et al. Proliferation of Aedes aegypti in urban environments mediated by the availability of key aquatic habitats. Sci. Rep. 10, 12925 (2020).

15. Ajelli, M. et al. Host outdoor exposure variability affects the transmission and spread of Zika virus: Insights for epidemic control. PLoS Negl. Trop. Dis. 11, e0005851 (2017).

16. Wilke, A. B. B., Benelli, G. \& Beier, J. C. Beyond frontiers: On invasive alien mosquito species in America and Europe. PLoS Negl. Trop. Dis. 14, 7864 (2020). 
17. Medlock, J. M. et al. Detection of the invasive mosquito species Aedes albopictus in southern England. Lancet Infect. Dis. 17, 140 (2017).

18. Reiter, P. Aedes albopictus and the world trade in used tires, 1988-1995: The shape of things to come?. J. Am. Mosq. Control Assoc. 14, 83-94 (1998).

19. Eastwood, G., Cunningham, A. A., Kramer, L. D. \& Goodman, S. J. The vector ecology of introduced Culex quinquefasciatus populations, and implications for future risk of West Nile virus emergence in the Galápagos archipelago. Med. Vet. Entomol. 33, 44-55 (2019).

20. Napp, S., Petrić, D. \& Busquets, N. West Nile virus and other mosquito-borne viruses present in Eastern Europe. Pathog. Glob. Health 112, 233-248 (2018).

21. Wilke, A. B. B., Wilk-da-Silva, R. \& Marrelli, M. T. Microgeographic population structuring of Aedes aegypti (Diptera: Culicidae). PLoS ONE 12, e0185150 (2017).

22. Multini, L. C., de Souza, A. L., Marrelli, M. T. \& Wilke, A. B. B. Population structuring of the invasive mosquito Aedes albopictus (Diptera: Culicidae) on a microgeographic scale. PLoS ONE 14, e0220773 (2019).

23. Wilke, A. B. B., de Carvalho, G. C. \& Marrelli, M. T. Microgeographic population structuring of Culex quinquefasciatus (Diptera: Culicidae) From São Paulo, Brazil. J. Med. Entomol. 54, 1582-1588 (2017).

24. Wilk-da-Silva, R., de Souza Leal Diniz, M. M. C., Marrelli, M. T. \& Wilke, A. B. B. Wing morphometric variability in Aedes aegypti (Diptera: Culicidae) from different urban built environments. Parasit. Vectors 11, 561 (2018).

25. Dyar, G. \& Knab, F. The larvae of Culicidae classified as independent organisms. J. N. Y. Entomol. Soc. 14, 169-230 (1906).

26. Laurito, M., Briscoe, A. G., Almirón, W. R. \& Harbach, R. E. Systematics of the Culex coronator complex (Diptera: Culicidae): Morphological and molecular assessment. Zool. J. Linn. Soc. 182, 735-757 (2018).

27. Demari-Silva, B. et al. Wing Morphometry and genetic variability between Culex coronator and Culex usquatus (Diptera: Culicidae), two sibling species of the coronator group. J. Med. Entomol. 54, 901-908 (2017).

28. Alto, B. W., Connelly, C. R., O’Meara, G. F., Hickman, D. \& Karr, N. Reproductive biology and susceptibility of Florida Culex coronator to infection with West Nile virus. Vector-Borne Zoonotic Dis. 14, 606-614 (2014).

29. Unlu, I., Kramer, W. L., Roy, A. F. \& Foil, L. D. Detection of West Nile virus RNA in mosquitoes and identification of mosquito blood meals collected at alligator farms in Louisiana. J. Med. Entomol. 47, 625-633 (2010).

30. CDC. Mosquito species in which West Nile virus has been detected. Centers for disease control and prevention. https://www.cdc. gov/westnile/resources/pdfs/Mosquito\%20Species\%201999-2012.pdf (2017).

31. CDC Arbovirus Catalog. Centers for disease control and prevention. https://wwwn.cdc.gov/Arbocat/Default.aspx (2018).

32. Scholte, E. J. et al. Introduction and control of three invasive mosquito species in the Netherlands, July-October 2010. Eurosurveillance 15, 1-4 (2010).

33. Reiter, P. \& Sprenger, D. The used tire trade: A mechanism for the worldwide dispersal of container breeding mosquitoes. J. Am. Mosq. Control Assoc. 3, 494-501 (1987).

34. Eritja, R, et al. Worldwide invasion of vector mosquitoes: Present European distribution and challenges for Spain. Issues in Bioinvasion Science 87-97 (Springer, 2005).

35. Connelly, C. R., Alto, B. W. \& O'Meara, G. F. The spread of Culex coronator (Diptera: Culicidae) throughout Florida. J. Vector Ecol. 41, 195-199 (2016).

36. Wilke, A. B. B. et al. Urbanization creates diverse aquatic habitats for immature mosquitoes in urban areas. Sci. Rep. 9, 15335 (2019).

37. LaDeau, S. L., Leisnham, P. T., Biehler, D. \& Bodner, D. Higher mosquito production in low-income neighborhoods of Baltimore and Washington, DC: Understanding ecological drivers and mosquito-borne disease risk in temperate cities. Int. J. Environ. Res. Public Health 10, 1505-1526 (2013).

38. Guedes, M. L. P. \& Navarro-Silva, M. A. Mosquito community composition in dynamic landscapes from the Atlantic Forest biome (Diptera, Culicidae). Rev. Bras. Entomol. 58, 88-94 (2014).

39. Miami-Dade County. Homeless trust census results and comparison. https://www.homelesstrust.org/library/january-homelesscensus-results-and-comparison-2018-2019.pdf (2019).

40. Blosser, E. M. \& Burkett-Cadena, N. D. Culex (Melanoconion) panocossa from peninsular Florida, USA. Acta Trop. 167, 59-63 (2017).

41. Blosser, E. M. \& Burkett-Cadena, N. D. Oviposition strategies of Florida Culex (Melanoconion) mosquitoes. J. Med. Entomol. 54, $812-820$ (2017).

42. Medeiros-Sousa, A. R., Fernandes, A., Ceretti-Junior, W., Wilke, A. B. B. \& Marrelli, M. T. Mosquitoes in urban green spaces: using an island biogeographic approach to identify drivers of species richness and composition. Sci. Rep. 7, 17826 (2017).

43. De Carvalho, G. C. et al. Composition and diversity of mosquitoes (Diptera: Culicidae) in urban parks in the South region of the city of São Paulo, Brazil. Biota Neotrop. 17, e20160274 (2017).

44. Wilke, A. B. B., Medeiros-Sousa, A. R., Ceretti-Junior, W. \& Marrelli, M. T. Mosquito populations dynamics associated with climate variations. Acta Trop. 166, 343-350 (2016).

45. Lizzi, K. M., Qualls, W. A., Brown, S. C. \& Beier, J. C. Expanding integrated vector management to promote healthy environments. Trends Parasitol. 30, 394-400 (2014).

46. WHO. Handbook for Integrated Vector Management (World Health Organization, Geneva, 2012).

47. Pagac, B. B. et al. Incursion and establishment of the Old World arbovirus vector Aedes (Fredwardsius) vittatus (Bigot, 1861) in the Americas. Acta Trop. 213, 105739 (2021).

48. United States Environmental Protection Agency. Growing for a sustainable future: Miami-Dade County urban development boundary assessment. http://www.epa.gov/smartgrowth/pdf/Miami-Dade_Final_Report_12-12-12.pdf (2012).

49. Blackmore, C. G. M. et al. Surveillance results from the first West Nile virus transmission season in Florida, 2001. Am. J. Trop. Med. Hyg. 69, 141-150 (2003).

50. Florida Department of Health. http://www.floridahealth.gov/diseases-and-conditions/mosquito-borne-diseases/_documents/ alert-dade-wnv-human-10-19-20.pdf (2020)

51. Wilke, A. B. B. et al. Assessment of the effectiveness of BG-Sentinel traps baited with $\mathrm{CO}_{2}$ and BG-Lure for the surveillance of vector mosquitoes in Miami-Dade County, Florida. PLoS ONE 14, e0212688 (2019).

52. Darsie, R. F. Jr. \& Morris, C. D. Keys to the adult females and fourth-instar larvae of the mosquitoes of Florida (Diptera, Culicidae). 1st ed. Vol. 1. Tech Bull Florida Mosq Cont Assoc (2000).

53. Silverman, B. W. Density Estimation for Statistics and Data Analysis. Monographs on Statistics and Applied Probability, Number 26. Boca Raton; Routledge. 176 pp. https://doi.org/10.1201/9781315140919.

\section{Acknowledgements}

We thank the staff of the Miami-Dade County Mosquito Control Division for their help in the processing and identification of the mosquitoes. 


\section{Author contributions}

A.B.B.W., C.V., and J.C.B., conceived of and designed the study. A.C., C.V. and J.M. were responsible for the mosquito collection and taxonomic identification. A.B.B.W., C.V., G.C., and J.C.B developed the study methodology and data analysis methodologies. A.B.B.W., and C.V., were responsible for the implementation of the study. A.B.B.W. and C.V., collected and analyzed the data and prepared the original figures. A.B.B.W. wrote the original draft of the paper. All authors contributed to reviewing and editing the paper. C.V., J.C.B., W.D.P., were responsible for the project administration, funding acquisition, resources, supervision and validation of this study.

\section{Funding}

This research was supported by the Miami-Dade Mosquito Control Division and by the CDC (https://www. cdc.gov/) grant 1U01CK000510-05: Southeastern Regional Center of Excellence in Vector-Borne Diseases: The Gateway Program. CDC had no role in the design of the study and collection, analysis, and interpretation of data and in writing the manuscript.

\section{Competing interests}

The authors declare no competing interests.

\section{Additional information}

Correspondence and requests for materials should be addressed to A.B.B.W.

Reprints and permissions information is available at www.nature.com/reprints.

Publisher's note Springer Nature remains neutral with regard to jurisdictional claims in published maps and institutional affiliations.

(c) (i) Open Access This article is licensed under a Creative Commons Attribution 4.0 International License, which permits use, sharing, adaptation, distribution and reproduction in any medium or format, as long as you give appropriate credit to the original author(s) and the source, provide a link to the Creative Commons licence, and indicate if changes were made. The images or other third party material in this article are included in the article's Creative Commons licence, unless indicated otherwise in a credit line to the material. If material is not included in the article's Creative Commons licence and your intended use is not permitted by statutory regulation or exceeds the permitted use, you will need to obtain permission directly from the copyright holder. To view a copy of this licence, visit http://creativecommons.org/licenses/by/4.0/.

(c) The Author(s) 2021 